\title{
Shreya Atrey, Intersectional Discrimination
}

(2019) Oxford University Press

Oxford, $224 \mathrm{pp}$.

\author{
Víctor Collí Ek \\ Universidad Autónoma de Campeche \\ ORCID ID 0000-0002-8524-6055 \\ vimcolli@uacam.mx
}

\section{Cita recomendada:}

Collí Ek, V. (2020). Shreya Atrey, Intersectional Discrimination. Eunomía. Revista en Cultura de la Legalidad, 19, pp. 612-615.

doi: https://doi.org/10.20318/eunomia.2020.5733

Shreya Atrey, recién nombrada profesora asociada de Derecho Internacional de los Derechos Humanos de la Universidad de Oxford y cercana colaboradora del Human Rights Hub de dicha prestigiosa universidad, ve a finales de 2019 publicado «Intersectional Discrimination». En este libro expone su inquietud sobre cómo aparejar la discriminación interseccional, la normativa sobre no discriminación y la justiciabilidad. Es un libro que nos invita a replantearnos los patrones establecidos hasta ahora. Su intención subraya es modesta, esto es, dar los primeros pasos en esa línea, pero su lectura nos obliga a pensar profundamente.

En general el libro se desenvuelve a partir de dos líneas argumentativas básicas. La primera sobre por qué la discriminación interseccional debe existir como una categoría específica en el derecho a la no discriminación, y para ello ofrece una perspectiva, teórica, conceptual y doctrinal. La segunda línea argumentativa es sobre por qué ha sido difícil para los sistemas jurisdiccionales alrededor del mundo el abordar de manera adecuada la discriminación interseccional. Para ello se hace una exploración comparativa en decisiones tomadas por diversos tribunales como la Corte Suprema de los Estados Unidos, la Corte Suprema del Reino Unido, la Corte de Sudáfrica, de la India, la Corte Europea de Derechos Humanos, la Corte Europea de Justicia y algunos organismos internacionales como el de CEDAW. Este es el marco 
dentro del que se desarrolla y desenvuelve el libro, el cual está organizado en cuatro capítulos.

En el primer capítulo «The Project: Realizing Interseccionality in Discrimination Law», nos recuerda que el objetivo del libro es hacer visible la interseccionalidad y, en concreto, hacerla viable en la legislación antidiscriminación. Para ello hay dos grandes preguntas: La primera es cómo la interseccionalidad ha sido concebida en la legislación antidiscriminación hasta ahora, y la segunda cómo debe ser concebida de una manera que realmente responda a sus principios básicos. El capítulo es para la autora paradójico, ya que a pesar de haber pasado 30 años desde el trabajo seminal de Crenshaw aún este libro necesita ser escrito. El marco normativo en el que se desarrolla la legislación antidiscriminación está diseñado o parece serlo de una manera muy robusta para abordar, tanto en la teoría como en la práctica, la discriminación vista desde un solo eje. Sin embargo, su afirmación es que la interseccionalidad es fundamentalmente compatible con tal marco normativo. Esto no la desilusiona, sino que más bien le plantea un reto con la pregunta: ¿qué se necesita para relacionar el marco normativo y su conjunto con la discriminación interseccional? Y a ello se abocará en los siguientes capítulos.

En el segundo capítulo "The Theory: Outlining the Intersectional Framework» el objetivo es delinear, defender y aplicar las principales líneas del marco de la teoría y la práctica de la interseccionalidad. Es profundamente interesante la identificación de las 5 líneas para definir dicho marco teórico básico: La atención a la relación entre igualdad y diferencia, y la relación con los patrones de desventaja grupal, la consideración como un todo con integridad, en su contexto completo, con el propósito de llevarlo a una concepción amplia y con un objetivo transformador. Esto es lo que para la autora representa la base intelectual de la interseccionalidad y que a su vez es la categoría base de la discriminación interseccional que la define. Se analiza en el capítulo la intervención de grandes autoras que tocaron la interseccionalidad como Kimberlé Williams Crenshaw y otras como Ángela Harris, Adrien Katherine, Patricia Williams, entre muchas otras. Es importante subrayar el núcleo básico de identificación de la interseccionalidad una vez más, para la autora tiene cinco principales líneas: La primera concerniente con el rastreo de la igualdad y diferencia en las experiencias pasadas en entidades grupales múltiples. La segunda concerniente con el rastreo de igualdad y diferencia en patrones de desventaja de grupo, entendido en términos amplios de subordinación, marginalización, violencia, desempoderamiento, privación, explotación y todas las otras formas de desventaja sufridas por grupos sociales. Tercera, estas desventajas deben ser consideradas como un todo, esto es en integridad. Cuarta, la interseccionalidad sólo puede ser apreciada en su completo contexto socioeconómico, cultural y político, porque así se moldean las identidades de las personas y los patrones de desventaja grupal asociados con ellas. Esto es importantísimo en el discurso planteado por la autora. Por último, el propósito del análisis interseccional es concebir más ampliamente los objetivos transformadores, que remuevan, rectifiquen y reformen las desventajas sufridas por los grupos interseccionales.

El capítulo tercero «The Concept: Understanding the Category on Intersectional Discrimination» aborda lo que la autora llama el «continuum», esto es, las diferentes categorías de discriminación que pueden ser y han sido analizadas en la jurisprudencia de los diversos tribunales que el libro explora. Para ello nos expone en términos generales 5 diferentes categorías: Discriminación en un solo eje, discriminación múltiple, discriminación aditiva, discriminación incrustada y discriminación interseccional. Ahora bien, antes de hacer el relato de cada una de las categorías la autora se refiere al elemento fundamental que hay que tomar en cuenta para poder determinar la posibilidad de que un tribunal, al momento de resolver un 
caso bajo alguna de las categorías, pueda hacerlo por medio de la categoría de discriminación interseccional, esto es, la causalidad, y sobre ella afirma primero que hay que delimitar qué causa la discriminación. Una afirmación es importante de la autora: para probar la discriminación no es necesario nada más que mostrar el lazo causal entre el acto erróneo y sus consecuencias discriminatorias, sino además que el acto y consecuencia fluyen de ciertos tipos de identidades reconocidas cómo motivos o características personales. Dice la autora que a pesar de que tradicionalmente el derecho antidiscriminación ha asumido que solamente hay una y un motivo que causa la discriminación en un caso particular, se pide mantener una mente abierta sobre la posibilidad de discriminación debido a un acto u omisión que puede ser directamente basado en uno o más motivos, o indirectamente dirigido a un efecto o impacto que es sufrido en uno o más motivos. Esto es lo que va a ir marcando el llamado "continuum» que llevará desde las discriminación de un solo eje hasta la discriminación interseccional.

El capítulo cuarto está dividido en siete secciones. Su objetivo es reencauzar de la teoría para acomodar a la discriminación interseccional y generar condiciones de posibilidad para su justiciabilidad. La primera analiza los diferentes textos legislativos y constitucionales, para concluir que no depende tanto de la manera en que la norma está redactada sino la interpretación que se le da a la misma, la posibilidad de analizar casos bajo la lupa de la interseccionalidad. La segunda sección analiza los motivos de la discriminación y los criterios para identificar motivos análogos. Esto es importante porque abre aún más la posibilidad de que un asunto pueda ser analizado bajo los criterios de interseccionalidad. Afirma que es importante expandir el alcance de los motivos para que se puedan reflejar en mejor medida las desventajas sufridas por la gente debido a sus propias identidades. La sección tercera analiza las formas de discriminación directa e indirecta y subraya el problema de mantener en términos estrictos esta distinción, específicamente tratándose de la discriminación interseccional, en donde una aproximación de la mezcla entre ambas pudiera tener un mejor resultado. La sección cuarta analiza el marco de la interseccionalidad, necesario para poder identificar patrones de desventaja de grupo y los daños en los casos de interseccionalidad. Este marco es un requisito previo para el estudio de la discriminación, pero el que debe ser sostenido por una rica concepción de la discriminación, lo cual pudiera llevar a que la corte o los tribunales sean conscientes de la interseccionalidad. En ese sentido, el marco de la interseccionalidad y la concepción de la discriminación de las Cortes operan una con la otra.

La sección quinta analiza el papel de la comparación para determinar la discriminación y sostiene que para poder ser productiva la comparación tiene que poseer una aproximación holística y contextual. Solo así podrán abordarse los múltiples motivos de discriminación y su inadecuación. De acuerdo con la autora, los análisis de discriminación principalmente conllevan dos pasos: 1. Sobre si ha habido un impacto discriminatorio o diferenciado basado en un motivo. 2. Sobre si la discriminación es incorrecta. La sección 6 aborda la interrogante de si una discriminación en específico puede estar justificada. Las preguntas ¿deberíamos de permitir estas justificaciones para la discriminación interseccional?, y de ser así ¿cómo debemos juzgarlas? Estas preguntas se responden de diferentes maneras de acuerdo con la autora, una de ellas es el establecer una distinción entre discriminación directa e indirecta, otra manera es a través de motivos particulares. Junto a esto, entra en la discusión de un tema importante en la justiciabilidad de derechos, que es la deferencia y el margen de apreciación. En esta sección se analiza el papel de, por ejemplo, la proporcionalidad como estándar de revisión judicial.

La sección séptima se refiere a la carga de la prueba -y como toda discusión sobre Derechos Humanos, por ejemplo, en el estándar de revisión de 
proporcionalidad-y se discute la pregunta de sobre quién debe probar, quién tiene la obligación para ello, para llegar a una reflexión en donde se establezca, si no a favor del demandante, sí un diálogo y una obligación por parte de los tribunales de una aproximación no solamente cuantitativa sino cualitativa a las pruebas.

En la sección octava se habla sobre los remedios que deben le determinarse cuando se habla de discriminación interseccional probada. Dos preguntas deben abordarse según la autora al tratarse de este tema. La primera si la discriminación interseccional debe considerar una indemnización monetaria agravada. La segunda si debe llegar nada más que a la persona demandante e igualmente a aquellas personas en su posición o si debe extenderse a cualquiera que comparta las desventajas del demandante. La autora recurre al caso Bhe v Magistrate, Khayelitsa de la Corte de Sudáfrica calificándolo de extraordinario, un raro ejemplo de remedios estructurales, que reconociendo las limitaciones para determinar los remedios por parte de los tribunales parece inclinarse justamente por lograr un efecto estructural en dichas determinaciones.

La autora en las primeras páginas del libro subraya con mucha claridad cual es el objetivo de este: ¿cómo puede en la práctica el derecho antidiscriminación ser re-imaginado para abrigar justamente la interseccionalidad? Me parece que este objetivo se cumple. Reconociendo que se trata de un pequeño paso dentro de una gran empresa, la líneas planteadas en el libro nos dejan ver que ciertamente es posible la justiciabilidad en términos de interseccionalidad. Solo falta imaginación, conocimiento, atrevimiento, inventiva. Al llevarnos de la mano desde las perspectivas teóricas, doctrinales y conceptuales nos permite ver que aunque aún en las primeras etapas, sí encontramos casos donde se ha trabajado en ello. Esto nos permite igualmente concluir de que es posible, solo necesitamos poner la atención y ver desde una perspectiva de conjunto. Es una tarea sin duda indispensable, pensar la discriminación no solo desde un solo eje o motivo, sino verla desde la realidad misma, ver las carencias y necesidades de las personas en su diversidad personal y, con ello, dar un paso más hacia una justiciabilidad más humana. 